\title{
Anti-tumor effects of AMT in the renal cell carcinoma model
}

\author{
MARCELLO CABALLERO ${ }^{1 *}$, JÜRGEN SCHEELE ${ }^{3,4 *}$, UTE ZIRRGIEBEL ${ }^{2}$, NORBERT ESSER ${ }^{2}$, \\ CHRISTOPH SCHÄCHTELE ${ }^{2}$, JENS SOLTAU ${ }^{1}$, JOCHEN RENTSCHLER ${ }^{1}$, \\ KLAUS DIERGARTEN $^{3}$ and JOACHIM DREVS ${ }^{1}$ \\ ${ }^{1}$ Cancer Hospital Sanafontis; ${ }^{2}$ ProQinase GmbH; ${ }^{3}$ AURON Healthcare GmbH; \\ ${ }^{4}$ Departments of Pharmacology I and Medicine I, University of Freiburg Medical Center, Freiburg, Germany
}

Received July 6, 2009; Accepted August 20, 2009

DOI: 10.3892/or_00000624

\begin{abstract}
Auron-Misheil-Therapy (AMT) is a defined but unique combination of approved pharmaceuticals. It consists of insulin, chlorpheniramine and an aqueous camomile extract, and it has been successfully applied clinically in late-stage cancer patients. The purpose of this study was to elucidate the anti-tumor efficacy of AMT in a validated murine renal cell carcinoma animal model (RENCA). There were two independent studies; each animal group consisted of 16 mice. During a 6-week pretreatment period, vehicle (group A) and AMT (1.6 mg/kg/d) (group B) were administered once daily in a 5 days/week schedule either intramuscularly or subcutaneously. Tumor challenge at day 0 was followed by a 3-week treatment period (either vehicle or AMT once daily intramuscularly for 21 days consecutively). In study 2 the AMT dosage was increased up to 4 -fold by doubling individual doses and switching to a twice daily schedule. The injections were all intramuscular. With the exception of group D, a six-week pretreatment period preceded the tumor challenge at day 0 . Tumor challenge was followed by a 3-week treatment period (vehicle, AMT at either $3.2 \mathrm{mg} / \mathrm{kg} / \mathrm{d}$ ) (group A) or $6.4 \mathrm{mg} / \mathrm{kg} / \mathrm{d}$ (group B), or $\mathrm{AMT}_{0}$, an AMT preparation which does not stimulate IL-6 secretion $(6.4 \mathrm{mg} / \mathrm{kg} /$ $\mathrm{d}$, group C) continuously for 21 days. AMT administration for group D $(6.4 \mathrm{mg} / \mathrm{kg} / \mathrm{d})$ was limited to the treatment period from day 1 to 21 . All mice were sacrificed 21 days after tumour transplantation. AMT administration was safe and well tolerated, and significantly reduced primary tumor volume in pretreated animals. The effective route of application was intramuscular, with dose escalation resulting in an improved
\end{abstract}

Correspondence to: Dr Joachim Drevs, Cancer Hospital Sanafontis, An den Heilquellen 2, D-79111 Freiburg, Germany

E-mail:drevs@sanafontis.com

${ }^{*}$ Contributed equally

Key words: Auron-Misheil-Therapy, insulin, chamomile, chlorpheniramine, RENCA anti-tumor effect. This is the first demonstration of a significant anti-tumorigenic effect of AMT in a validated tumor model.

\section{Introduction}

Auron-Misheil Therapy (AMT) is a defined combination of known, approved, and widely used pharmaceuticals. It consists of three active ingredients: insulin, chlorpheniramine and an aqueous camomile extract, and is administered intra-muscularly to support patients in various diseases, with a focus on late-stage cancer. The novelty of AMT is its unique combination of these pharmaceuticals; so far it has not been tested preclinically with respect to its anti-tumor potential.

Since 1989 AMT has been administered mainly in countries of the Middle East to late-stage cancer patients or patients suffering from other serious illnesses (1). Because the outcome of therapy was promising, $\sim 50 \%$ of the patients experienced a clinical benefit response (CBR), a research and development program to investigate the pharmacological and toxicological properties of AMT was initiated. The focus of the present study was to investigate the possibility of a dosedependent anti-tumor effect of AMT, to assess the effect of AMT on the immune system, and to validate the efficacy of intramuscular administration of AMT.

In AMT three well-known components, each with cancerrelevant characteristics, are combined $(2,3)$. Cancer patients often experience deregulated glucose metabolism (4). Exogenous addition of insulin can help to normalize glucose levels (5) and, more importantly, insulin is regarded as a potent biologic response modifier when its role in the insulin potentiation therapy concept is discussed (6). Here it is proposed that insulin sensitises tumor cells by modifying cell membrane characteristics and increasing their rate of proliferation, which in turn renders tumor cells more vulnerable to the anti-proliferative effects of classical chemotherapeutics $(7,8)$. Recently, the addition of insulin to methotrexate in the treatment of patients with metastatic breast cancer improved clinical outcome (9), and the combination of gemcitabine and apigenin enhanced anti-tumor efficacy in vitro and in vivo (10).

Chlorpheniramine (also chlorphenamine, CPN) is a firstgeneration alkylamine antihistamine used in prevention of the symptoms of allergic conditions. Antihistamines are used 
Table I. Design of study 1.

\begin{tabular}{llll}
\hline Group & Dose per day & \multicolumn{1}{c}{ Schedule $^{\text {a }}$} \\
\hline A Control & Saline & day -42 to -1 daily, 5 days/week & i.m. \\
& Saline & day 1 to 21 daily 7 days/week & i.m. \\
A AMT & $1.6 \mathrm{mg} / \mathrm{kg}$ & day -42 to -1 daily 5 days $/$ week & i.m. \\
& $1.6 \mathrm{mg} / \mathrm{kg}$ & day 1 to 21 daily 7 days/week & i.m. \\
B Contro & Saline & day -42 to -1 daily 5 days/week & i.m. \\
& Saline & day 1 to 21 daily 7 days/week & s.c. \\
B AMT & $1.6 \mathrm{mg} / \mathrm{kg}$ & day -42 to- 1 daily 5 days/week & i.m. \\
& $1.6 \mathrm{mg} / \mathrm{kg}$ & day 1 to 21 daily 7 days/week &
\end{tabular}

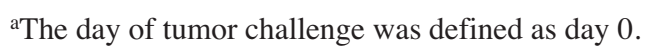

as supportive cancer medication to alleviate cancer pain (11). It has also been shown that, like insulin, antihistamines have a chemotherapy sensitizing effect on tumor cells $(12,13)$. In addition to this well-established function, it has been demonstrated that chlorpheniramine has anti-tumorigenic potential. Preclinical evidence for antiproliferative effects of chlorpheniramine on breast cancer cells (14), in in vivo studies of Ehrlich carcinoma (15), and a possible chemopreventive function in colon cancer, support a promising role for chlorpheniramine as a component of AMT in anti-cancer treatment regimens (16).

Camomile extracts have the longest history of medical efficacy (17). Currently there is evidence that the flavonoids apigenin and luteolin are relevant ingredients of aqueous camomile extracts. It was shown that apigenin has antiproliferative effects on various human cancer cells, while untransformed cells are not affected (18). There is also evidence that the protein kinase Akt plays a functional role in the anti-tumorigenic effect of apigenin in PC3 prostate carcinoma cells (19). In addition, platelet-derived growth factor receptor (PDGFR) has been identified as the molecular target of luteolin (20). The anti-inflammatory effects of camomile extract have been demonstrated in cell culture as well as in in vivo studies (21). Experiments in nude mice correlate the anti-tumorigenic activity of apigenin with antiangiogenic potential (22). There are indications that the three active components of AMT, with their individual effects on complex physiological regulatory systems, may act synergistically (2).

The clinically relevant murine renal cell carcinoma (RENCA) model has been previously shown to successfully detect anti-tumor effects of numerous validated anti-cancer agents (23-25). In this model, primary kidney tumors are induced by subcapsular renal injection of RENCA cells with subsequent development of metastases in the lung, lymph nodes and spleen (26). Besides the general observation of tolerability and safety of AMT administration, we monitored primary tumor growth, the degree of lung metastases, and the effect of AMT on the immune system. Since the intramuscular route of application has not been validated for herbal components, the experiment was designed to obtain insight into how essential this mode of application might be. In short, despite positive clinical experience with AMT and a number of publications supporting its promising role as an anti-cancer agent, thus far there exists very limited in vivo data to establish AMT's anti-tumor efficacy.

\section{Materials and methods}

Compounds. AMT (Auron-Misheil-Therapy) was provided as a 3 vial formulation by Auron $\mathrm{GmbH}$ (MCS Microcarrier Systems GmbH, Neuss, Germany). For study 1 (batch-no.) AMT 2003 Cam (5228), AMT 2003 Vit(+) (5229) and AMT 2003 Ins (5230) were used. For study 2 AMT 2003 Cam (6091), AMT $2003 \mathrm{Vit}(+)$ (6090), and AMT zero IL6 (AMT , 6089) were used. All components were stored at $4^{\circ} \mathrm{C}$.

Preparation of compounds. AMT was prepared by mixing defined amounts of the 3 individually supplied components. For $10 \mathrm{ml}$ of AMT, $5 \mathrm{ml}$ AMT $2003 \mathrm{Cam} \mathrm{H}$ were transferred into an empty mixing vial. AMT $2003 \mathrm{Vit}(+)(4.75 \mathrm{ml})$ and $0.25 \mathrm{ml}$ AMT 2003 Ins were added. All three components were mixed thoroughly. This procedure was performed prior to each application.

Cell culture. For animal experiments, RENCA cells (Professor H. Pahl, University Freiburg, Germany) were originally generated from a tumor that arose spontaneously in the kidney of BALB/c mice. Monolayers of murine RENCA cells were grown in RPMI-1640 supplemented with $10 \%$ FCS, $2 \mathrm{mM}$ L-glutamine, $100 \mathrm{U}$ penicillin/ml and $100 \mu \mathrm{g}$ streptomycin $/ \mathrm{ml}$. RENCA cells were cultured in a humidified atmosphere of $95 \%$ air and $5 \% \mathrm{CO}_{2}$ at $37^{\circ} \mathrm{C}$. Media were routinely changed every 3 days. Cells were released from the tissue flasks by treatment with $0.05 \%$ trypsin/EDTA. For the experiments, cells were collected during the logarithmic growth phase.

Animal experiments. All experiments were carried out in accordance with the guidelines of the Ethics Committee of the local authorities (Regierungspräsidium Freiburg, Germany AZ-Nr.9185.82/3/277). Female BALB/c mice were used at 6-8 weeks of age (approximate weight $20 \mathrm{~g}$ ). After the animals were anaesthetized with $0.5-1.5$ volume percent isoflurane with an oxygen flow of $1.5 \mathrm{l} / \mathrm{min}$, the injection of $4 \times 10^{5}$ cells in $25 \mu 1$ aliquots into the subcapsular space of the left kidney was performed through a flank incision. 


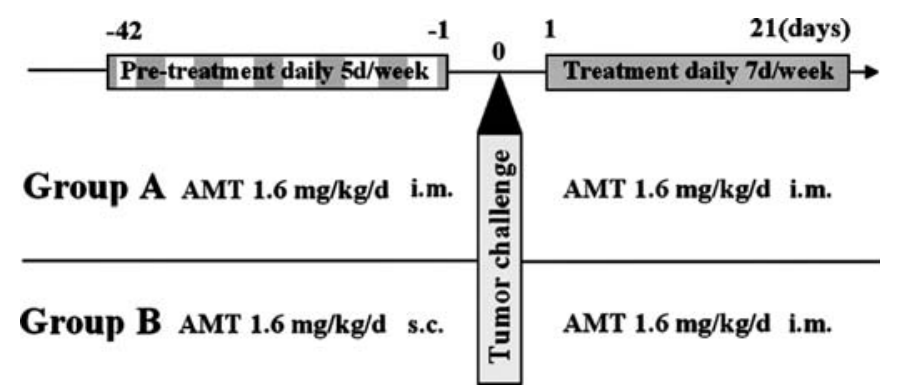

Figure 1. Experimental design of study 1 with pretreatment with AMT on 5 days per week, administered either i.m. (group A) or s.c. (group B). Continuous treatment after innoculation of tumor cells (tumor challenge at day 0) was administered in both groups i.m.

Table II. Design of study 2.

\begin{tabular}{|c|c|c|}
\hline Group & Dose per day & Schedule $^{b}$ \\
\hline A Control & $\begin{array}{l}\text { Saline day }-42 \text { to }-1 \\
\text { Saline day } 1 \text { to } 21\end{array}$ & $\begin{array}{l}\text { bd, } 5 \text { days/week } \\
\text { bd, } 7 \text { days/week }\end{array}$ \\
\hline A AMT & $\begin{array}{l}3.2 \mathrm{mg} / \mathrm{kgday}-42 \text { to }-1 \\
3.2 \mathrm{mg} / \mathrm{kgday} 1 \text { to } 21\end{array}$ & $\begin{array}{l}\text { bd, } 5 \text { days/week } \\
\text { bd, } 7 \text { days/week }\end{array}$ \\
\hline B-D Control & $\begin{array}{l}\text { Saline day }-42 \text { to }-1 \\
\text { Saline day } 1 \text { to } 19\end{array}$ & $\begin{array}{l}\text { bd, } 5 \text { days/week } \\
\text { bd, } 7 \text { days/week }\end{array}$ \\
\hline B AMT & $\begin{array}{l}6.4 \mathrm{mg} / \mathrm{kg} \text { day }-42 \text { to }-1 \\
6.4 \mathrm{mg} / \mathrm{kg} \text { day } 1 \text { to } 19\end{array}$ & $\begin{array}{l}\text { bd, } 5 \text { days/week } \\
\text { bd, } 7 \text { days/week }\end{array}$ \\
\hline $\mathrm{C} \mathrm{AMT}_{0}$ & $\begin{array}{l}6.4 \mathrm{mg} / \mathrm{kg} \text { day }-42 \text { tp }-1 \\
6.4 \mathrm{mg} / \mathrm{kg} \text { day } 1 \text { to } 19\end{array}$ & $\begin{array}{l}\text { bd, } 5 \text { days/week } \\
\text { bd, } 7 \text { days/week }\end{array}$ \\
\hline D AMT & $6.4 \mathrm{mg} / \mathrm{kg}$ day 1 to 19 & bd, 7 days/week \\
\hline
\end{tabular}

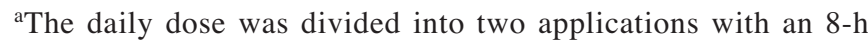
interval. All dosages i.m. ${ }^{\mathrm{b}}$ The day of tumor challenge was defined as day 0 .

The tumor cell injection induced progressive development of a primary tumor mass in the left kidney. One week after implantation, the primary tumor is usually macroscopically visible; after 10 days, spontaneous metastases will develop in regional lymph nodes, the lung, the peritoneum and the liver. The mean survival time of untreated RENCA-bearing mice is $\sim 28$ days.

Study design. Study 1: the first study consisted of two groups, $\mathrm{A}$ and B, each consisting of 16 female BALB/c mice (Table I). Preceding the implantation of RENCA tumor cells (tumor challenge) a 6-week pretreatment period was started at day -42 . During the pretreatment period vehicle (saline) and AMT $(1.6 \mathrm{mg} / \mathrm{kg} / \mathrm{d})$ were administered once daily in a 5 days/week schedule either i.m. (group A) or s.c. (group B). Tumor challenge at day 0 was followed by a 3 -week treatment period in which all animals received either vehicle (saline) or AMT once daily i.m. continously for 21 days (Fig. 1). At day 21 animals were sacrificed. Primary tumor weight and volume, lung weight and number of lung metastases were

\begin{tabular}{|c|c|c|}
\hline-42 & & 21(19) days \\
\hline Pretreatment i.m. b.d. 5d/week & & Treatment i.m. b.d. 7d/week \\
\hline Group A AMT $3.2 \mathrm{mg} / \mathrm{kg} / \mathrm{d}$ & \multirow{4}{*}{ 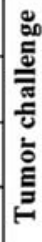 } & AMT $3.2 \mathrm{mg} / \mathrm{kg} / \mathrm{d}$ \\
\hline Group B AMT $6.4 \mathrm{mg} / \mathrm{kg} / \mathrm{d}$ & & AMT $6.4 \mathrm{mg} / \mathrm{kg} / \mathrm{d}$ \\
\hline Group C $\mathrm{AMT}_{0} 6.4 \mathrm{mg} / \mathrm{kg} / \mathrm{d}$ & & $\mathrm{AMT}_{0} 6.4 \mathrm{mg} / \mathrm{kg} / \mathrm{d}$ \\
\hline Group D & & AMT $6.4 \mathrm{mg} / \mathrm{kg} / \mathrm{d}$ \\
\hline
\end{tabular}

Figure 2. Experimental design of study 2 with AMT administered i.m. twice daily at two different doses. Group A, AMT $3.2 \mathrm{mg} / \mathrm{kg} / \mathrm{d}$; group B, AMT $6.4 \mathrm{mg} / \mathrm{kg} / \mathrm{d}$. Animals of group C received $\mathrm{AMT}_{0}$, with no IL-6 stimulating activity. In group D regular AMT was administered only during the treatment phase.

determined. Spleens of all animals were collected under sterile conditions and transferred immediately to FOCUS, Heidelberg for further investigation.

Study 2. In this follow-up study the dosage of AMT was increased up to 4 -fold compared with study 1 . This was achieved by doubling individual doses and switching to a twice daily schedule (Table II). All doses were administered i.m. Again, with the exception of group D, a 6-week pre-treatment period preceded the tumor challenge at day 0. During the pretreatment period, vehicle and AMT were administered twice daily for 5 days/week (Fig. 2). As in study 1, tumor challenge at day 0 was followed by a 3 -week treatment period during which all animals received either vehicle (two control groups for group A and groups B-D), AMT at either $3.2 \mathrm{mg} / \mathrm{kg} / \mathrm{d}$ (group A) or $6.4 \mathrm{mg} / \mathrm{kg} / \mathrm{d}$ (group B), or $\mathrm{AMT}_{0}$, an AMT preparation which does not stimulate IL-6 secretion (6.4 mg/kd/d, group C) continuously for 21 and 19 days respectively. AMT application for group D was limited to the treatment period from day 1 to 21 . At day 21 (group A) and day 19 (groups B-D) the animals were sacrificed. Primary tumor weight and volume, lung weight and number of lung metastases were determined.

Immune response monitoring. Spleens of animals from selected experimental groups were collected under sterile conditions and transferred immediately on wet ice for further investigation (FOCUS, Heidelberg). There, individual tissue cell cultures were established. Cells were left unstimulated or stimulated using beads loaded with CD3/28 as a means to activate T cells. After $16-20 \mathrm{~h}$ the supernatants from the individual cultures were analysed with respect to their content of IL-2, IL-4, IL-10, TNF- $\alpha$ and INF- $\alpha$. In general, this panel allows discrimination of Th1, Th2 and immune-suppressive activities of T cells from animals of the different treatment groups.

Statistics. Each animal group consisted of 16 mice, with a vehicle control group for every treatment schedule. Data analysis was performed using the unpaired t-test.

\section{Results}

Using the orthotopic RENCA model we investigated the anti-tumoral potential of AMT, a three-component mixture, 


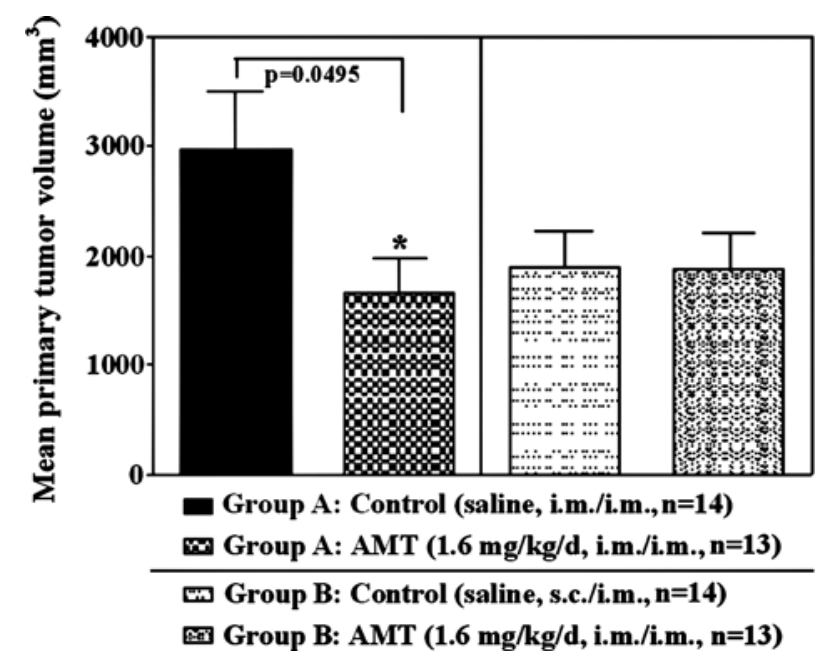

Figure 3. Study 1: primary tumor volume after pretreatment/treatment with $1.6 \mathrm{mg} / \mathrm{kg} / \mathrm{d}$ AMT vs. vehicle administered once daily either i.m./i.m. (group A) or s.c./i.m. (group B). Group A, shows a significant decrease in tumor volume after administration of AM i.m. during the pretreatment and treatment phases. Group B, shows no effect on primary tumor volume after administration of AMT s.c. during the pretreatment phase of the experiment.

known to successfully support late stage cancer patients. Due to the immune modulatory characteristics of AMT both studies presented here consisted of a 6-week pretreatment period before challenging the mice by injecting RENCA tumor cells into the left kidney. The route of application is of special interest, since clinical experience with AMT is based mainly on intramuscular administration. Therefore, we included a group of animals which received AMT during pretreatment subcutaneously.

Animal weights were monitored every other day and did not decline throughout the treatment phases of the studies. In general, during both studies no significant differences between control groups and treatment groups were observed. This finding was independent of the route of administration.

After three weeks of continous therapy with AMT $(1.6 \mathrm{mg} / \mathrm{kg} / \mathrm{d})$ its potential to interfere with tumor formation was determined. We analysed AMT effects with respect to the primary tumor volume and found a significant decrease when AMT was administered intramuscularly during the pretreatment as well as the treatment period (Fig. 3, group A). By contrast, tumor volumes of group B, with subcutaneously administered AMT during pretreatment, showed no difference compared to vehicle treated animals (Fig. 3, group B).

Since AMT was well tolerated in study 1 the promising anti-tumor efficacy of AMT was further investigated in study 2 implementing a dose-dense design: dose was doubled by applying AMT as in study 1, but twice daily [group A, (3.2 mg/kg/d)]. In addition, a 4-fold dose increase compared to study 1 was achieved by adminstering $3.2 \mathrm{mg} / \mathrm{kg}$ AMT twice daily [groups B, C and D, $(6.4 \mathrm{mg} / \mathrm{kg} / \mathrm{d})$ ].

Again, primary tumor volume was assessed, and while group A did not show a significant decrease, with group B $(6.4 \mathrm{mg} / \mathrm{kg} / \mathrm{d}$ AMT) the initial results of study 1 were confirmed (Fig. 4). To obtain more detailed experimental information on AMT mechanism, study 2 was varied by introducing $\mathrm{AMT}_{0}$, an $\mathrm{AMT}$ preparation that lacks the property of stimulating IL-6 release when tested in the relevant cell

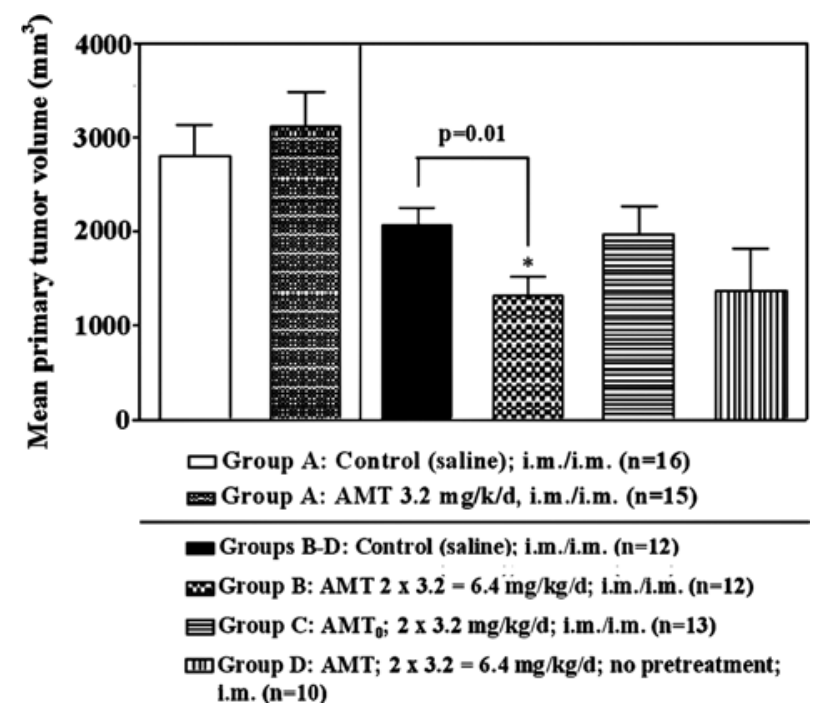

Figure 4. Study 2: primary tumor volume after pretreatment/treatment with AMT vs. vehicle control administered either b.i.d. with $3.2 \mathrm{mg} / \mathrm{ml} / \mathrm{d}$ (group A) or $6.4 \mathrm{mg} / \mathrm{ml} / \mathrm{d}$ (groups B, C, D). Group C received $\mathrm{AMT}_{0}$ with no IL-6 inducing activity. Group D received regular AMT, but no pretreatment.

culture model. In group $\mathrm{C}$, application of $\mathrm{AMT}_{0}$ with the identical dose and scheduling as the regular AMT (group B) did not interfere with primary RENCA tumor formation. With group D another experimental setting was introduced to examine whether AMT pretreatment is a general prerequisite for its anti-tumor activity. Regular AMT was applied with the increased dose of $6.4 \mathrm{mg} / \mathrm{kg} / \mathrm{d}$, but initiated after tumor challenge. Here, a trend to lower primary tumor volumes were observed, but the difference did not reach significance.

Using the RENCA tumor model it is possible to get insight into the anti-metastatic potential of the tested compounds. Table III summarizes the results of both studies with respect to tumor volume as shown in Figs. 3 and 4 and the onset of lung metastases and animal losses in each experimental group.

Efficacy of AMT to reduce formation of lung metastases was achieved solely in group B of study 2 with increased twice daily dosing up to $6.4 \mathrm{mg} / \mathrm{kg} / \mathrm{d}$. AMT had no effect on animal weight in any group, a fact that indicates a general tolerability; this finding was independent of the route of application. Neither did we observe any signs of irritation at the site of injection, even after numerous applications. However, in experimental groups B, C and D more animals in the treatment arms had to be sacrificed for ethical reasons.

Immune response monitored by assessing cytokine release was performed by preparing full spleen cell cultures and keeping them overnight either unstimulated or after stimulation with CD3/28. Firstly, the chosen RENCA tumor model displayed an immune suppressive effect: neither of the animals carrying a tumor reached the level of IL-2 secretion seen in control animals (Fig. 5). In addition, there is a clear, inverse relationship between tumor size and immune cell activity if animals are analyzed individually. Animals with large tumors responded with low IL-2 secretion whereas animals with small tumors had high levels of IL-2 in the supernatant (data not shown). However, this correlation was independent of the treatment with AMT. 
Table III. Results of study 1 and 2 with T/C values for tumor volumes, lung metastases (onset and number) and information on animal losses.

\begin{tabular}{|c|c|c|c|c|c|c|c|c|c|}
\hline & \multirow{2}{*}{$\begin{array}{l}\text { Daily dose } \\
\text { (mg/kg/d) }\end{array}$} & \multirow[t]{2}{*}{ Pretreatment } & \multirow[t]{2}{*}{ Route } & \multicolumn{2}{|c|}{ Efficacy T/C (\%) } & \multicolumn{3}{|c|}{ Lung metastases $\mathrm{T} / \mathrm{C}(\%)$} & \multirow{2}{*}{$\frac{\text { Animal loss }}{\mathrm{T} / \mathrm{C}(\%)}$} \\
\hline & & & & Tumor volume & p-value ${ }^{a}$ & Onset & Number & p-value ${ }^{a}$ & \\
\hline \multicolumn{10}{|l|}{ Study 1} \\
\hline Group A AMT & 1.6 & Yes & $\mathrm{im} / \mathrm{im}$ & 56 & 0.076 & 85 & 153 & $>0.3$ & 7 \\
\hline Group B AMT & 1.6 & Yes & $\mathrm{sc} / \mathrm{im}$ & 99 & $>0.3$ & 91 & 74 & $>0.3$ & 7 \\
\hline \multicolumn{10}{|l|}{ Study 2} \\
\hline Group A AMT & 3.2 & Yes & $\mathrm{im} / \mathrm{im}$ & 112 & $>0.3$ & 107 & 75 & $>0.3$ & 6 \\
\hline Group B AMT & 6.4 & Yes & $\mathrm{im} / \mathrm{im}$ & 64 & 0.017 & 67 & 3 & 0.21 & 9 \\
\hline Group C $\mathrm{AMT}_{0}$ & 6.4 & Yes & $\mathrm{im} / \mathrm{im}$ & 96 & $>0.3$ & 184 & 182 & $>0.3$ & 9 \\
\hline Group D AMT & 6.4 & No & ---/im & 67 & 0.12 & 140 & 184 & $>0.3$ & 25 \\
\hline
\end{tabular}

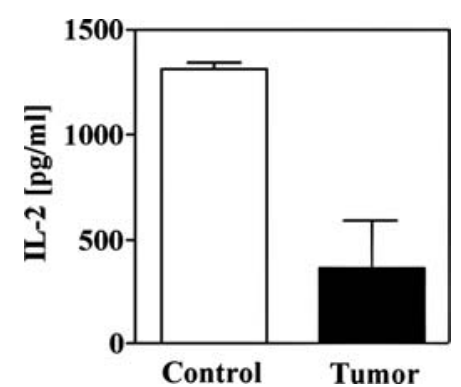

Figure 5. Cultured spleen cells of either non-tumor bearing control animals or generated from animals with developed RENCA tumors. After stimulation with CD3/28 IL-2 levels were determined in the supernatants. While in control cells this stimulation is followed by a robust IL-2 secretion, this response is suppressed in RENCA tumor cells.

In summary, AMT administered intra-muscularly during the pretreatment and treatment phases resulted in a significant reduction of primary tumor volume. But in spite of evidence supporting the positive effect of pretreatment, and the negative result obtained by using $\mathrm{AMT}_{0}$ which lacked IL-6 stimulating activity, the biological test system chosen to detect the effect of AMT on tumor-related immune suppression did not provide further mechanistic insight.

\section{Discussion}

We describe for the first time a significant effect of AMT on primary tumor growth and a trend to lower rates of lung metastases using the RENCA tumor model. A clear supportive function of AMT was already evident prior to tumor challenge, and this improved with the introduction of a dose-intense regimen: by increasing the AMT dose up to $6.4 \mathrm{mg} / \mathrm{kg} / \mathrm{d}$ a higher significance of the initially observed anti-tumor efficacy was reached. Moreover, with this increased AMT dose, applied solely during the treatment phase, a remarkable though not significant $30 \%$ reduction of primary tumor volume was observed. The onset of lung metastases was assessed, but the analysis was impeded by the high degree of variability of this parameter and the data did not reach significance. Notably, $30 \%$ fewer animals in group B of study 2 developed lung metastases. Since the renal cell carcinoma develops as a highly vascularized tumor the RENCA model is the suitable animal model to demonstrate an anti-angiogenic potential. In line with our findings, apigenin, the flavonoid found in camomile extracts, was found to suppress VEGF expression in A549 lung cancer cells (22).

Furthermore, the results presented here support intramuscular administration as the effective route for AMT. Pretreating the animals subcutaneously diminished the AMT effect on tumor volume completely, while a systematic difference (e.g. stress response) of these application modes can be excluded (27). Apparently, with the dosing in study 2 the maximal tolerated dose (MTD) of AMT was reached, which is most likely due to the effect of the relatively high levels of insulin that have not been adjusted with respect to physiological murine levels. Still, recent data confirm the anti-tumor potential of insulin. It has been shown that IGF-1 plasma levels correlate with delayed recurrence of colorectal lesions (28). The notion that high insulin levels are correlated with tumor progression in general (29) is partly disproved when analysing IGF-1 levels in postmenopausal breast cancer patients (30). We believe that the CBR seen after AMT application in the clinical setting is most likely correlated with long-term influence on the glucose metabolism (31), an aspect that cannot be assessed with the applied experimental model.

The components of AMT as well as the low-dose regimen that has been used successfully to treat a variety of indications led to the hypothesis that AMT function is caused by a general immunostimulatory effect. We complemented our regular expermental setting by a thorough analysis of a possible alleviation of the immune suppression caused by the RENCA tumor formation in the animals. The test system readily detected immune suppressive activity of RENCA tumor cells grown in vivo, which correlated with tumor size when analyzed in individual animals. However, we did not observe an improved cytokine release after AMT treatment. With $\mathrm{AMT}_{0}$ we tested an AMT preparation lacking the ability to stimulate IL-6, to assess whether this aspect of AMT action is inevitable for the overall effect. In the event, no anti-tumor efficacy was detected when $\mathrm{AMT}_{0}$ was applied. Therefore, the mechanism by which AMT exerts its immunostimulatory effect remains unclear and is still under investigation. 
Collectively, anti-tumor efficacy of AMT was demonstrated in two independent experiments, while its administration was safe, as previously shown in preclinical toxicological studies. With $6.4 \mathrm{mg} / \mathrm{kg} / \mathrm{d}$ the MTD for AMT in mice was reached, presumably because of the insulin levels involved.

\section{Acknowledgements}

We thank B. Giessen and S. Moor for performing the animal work and F. Zuehl for preparing the initial study.

\section{References}

1. Toure P, Drevs J, Weinsburg F, Niazi F and Diergarten K: Phase II study with Auron Misheil Therapy (AMT) in patients with Advanced Cervical Cancer (ACC). ASGO 15th Int Meeting, 2007.

2. Niazi F, Drevs J, Diergarten K, Dorn A, Maier A, Fiebig HH, Bruyns E and Scheele J: AMT: preclinical pharmacology studies. Int J Oncol 34: 1341-1352, 2009.

3. Scheele J, Diergarten K, Drevs J and Niazi FR: A Phase I trial assessing the safety, tolerability, pharmacokinetic and pharmacodynamic characteristics of single-dose Auron Misheil Therapy in healthy male subjects. J Clin Pharm Ther (In press).

4. Younes RN and Noguchi Y: Pathophysiology of cancer cachexia. Rev Hosp Clin Fac Med Sao Paulo 55: 181-193, 2000.

5. Argilés JM and López-Soriano FJ: Insulin and cancer. Int J Oncol 18: 683-687, 2001.

6. Hauser R and Hauser M: Treating cancer with insulin potentiation therapy. Beulah L and Press 2002

7. Ayre S, Garcia y Bellon D and Perez Garcia D Jr: Insulin, chemotherapy, and the mechanisms of malignancy: the design and the demise of cancer. Med Hypotheses 55: 330-334, 2000

8. Peacock J, Gorschboth CM and Norton JA: Impact of insulin on doxorubicin-induced rat host toxicity and tumor regression. Cancer Res 47: 4318-4322, 1987.

9. Lasalvia-Prisco E, Cucchi S, Vázquez J, Lasalvia-Galante E, Golomar W and Gordon W: Insulin-induced enhancement of antitumoral response to methotrexate in breast cancer patients. Cancer Chemother Pharmacol 53: 220-224, 2004.

10. Lee SH, Ryu JK, Lee KY, Woo SM, Park JJ, Yoo JW, Kim YT and Yoon YB: Enhanced anti-tumor effect of combination therapy with gemcitabine and apigenin in pancreatic cancer. Cancer Lett 259: 39-49, 2008.

11. Cameron LB: Neuropsychotropic drugs as adjuncts in the treatment of cancer pain. Oncology 65-71, 1992.

12. Robinson JB, Singh D, Bodurka-Bevers DC, Wharton JT, Gershenson DM and Wolf JK: Hypersensitivity reactions and the utility of oral and intravenous desensitization in patients with gynecologic malignancies. Gynecol Oncol 82: 550-558, 2001 .

13. Markman M, Kennedy A, Webster K, Petersen G, Kulp B and Belinson J: An effective and more convenient drug regimen for prophylaxis against paclitaxel-associated hypersensitivity reactions. J Cancer Res Clin Oncol 125: 427-429, 1999.

14. Medina M, García de Veas R, Morata P, Lozano J and Sánchez-Jiménez F: Chlorpheniramine inhibits the synthesis of ornithine decarboxylase and the proliferation of human breast cancer cell lines. Breast Cancer Res Treat 35: 187-194, 1995

15. Gómez-Fabre P, de Pedro E, Medina M, Núñez de Castro I and Márquez J: Polyamine contents of human breast cancer cells treated with the cytotoxic agents chlorpheniramine and dehydrodidemnin B. Cancer Lett 113: 141-144, 1997.
16. Wargovich MJ, Jimenez A, McKee K, Steele VE, Velasco M, Woods J, Price R, Gray K and Kelloff GJ: Efficacy of potential chemopreventive agents on rat colon aberrant crypt formation and progression. Carcinogenesis 21: 1149-1155, 2000.

17. McKay D and Blumberg J: A review of the bioactivity and potential health benefits of chamomile tea (Matricaria recutita L.). Phytother Res 20: 519-530, 2006.

18. Srivastava J and Gupta S: Antiproliferative and apoptotic effects of chamomile extract in various human cancer cells. J Agric Food Chem 55: 9470-9478, 2007.

19. Mirzoeva S, Kim ND, Chiu K, Franzen CA, Bergan RC and Pelling JC: Inhibition of HIF-1 alpha and VEGF expression by the chemopreventive bioflavonoid apigenin is accompanied by Akt inhibition in human prostate carcinoma PC3-M cells. Mol Carcinog 47: 686-700, 2008

20. Kim JH, Jin YR, Park BS, Kim TJ, Kim SY, Lim Y, Hong JT, Yoo HS and Yun YP: Luteolin prevents PDGF-BB-induced proliferation of vascular smooth muscle cells by inhibition of PDGF beta-receptor phosphorylation. Biochem Pharmacol 69: $1715-1721,2005$

21. Smolinski AT and Pestka JJ: Modulation of lipopolysaccharideinduced proinflammatory cytokine production in vitro and in vivo by the herbal constituents apigenin (chamomile), ginsenoside $\mathrm{Rb}$ (1) (ginseng) and parthenolide (feverfew). Food Chem Toxicol 41: 1381-1390, 2003.

22. Liu LZ, Fang J, Zhou Q, Hu X, Shi X and Jiang BH: Apigenin inhibits expression of vascular endothelial growth factor and angiogenesis in human lung cancer cells: implication of chemoprevention of lung cancer. Mol Pharmacol 68: 635-643, 2005.

23. Chang YS, Adnane J, Trail PA, Levy J, Henderson A, Xue D, Bortolon E, Ichetovkin M, Chen C, McNabola A, Wilkie D, Carter CA, Taylor IC, Lynch M and Wilhelm S: Sorafenib (BAY 43-9006) inhibits tumor growth and vascularization and induces tumor apoptosis and hypoxia in RCC xenograft models. Cancer Chemother Pharmacol 59: 561-574, 2007.

24. Oh HY, Kwon SM, Kim SI, Jae YW and Hong SJ: Antiangiogenic effect of ZD1839 against murine renal cell carcinoma (RENCA) in an orthotopic mouse model. Urol Int 75: 159-166, 2005.

25. Verheul HM, Hammers H, van Erp K, Wei Y, Sanni T, Salumbides B, Qian DZ, Yancopoulos GD and Pili R: Vascular endothelial growth factor trap blocks tumor growth, metastasis formation, and vascular leakage in an orthotopic murine renal cell cancer model. Clin Cancer Res 13: 4201-4208, 2007.

26. Ahn KS, Jung YS, Kim J, Lee H and Yoon SS: Behavior of murine renal carcinoma cells grown in ectopic or orthotopic sites in syngeneic mice. Tumour Biol 22: 146-153, 2001.

27. Meijer MK, Spruijt BM, van Zutphen LF and Baumans V: Effect of restraint and injection methods on heart rate and body temperature in mice. Lab Anim 40: 382-391, 2008.

28. Jacobs ET, Martínez ME, Alberts DS, Ashbeck EL, Gapstur SM, Lance P and Thompson PA: plasma insulin-like growth factor I is inversely associated with colorectal adenoma recurrence: a novel hypothesis. Cancer Epidemiol Biomarkers Prev 17: 300-305, 2008.

29. Paz K and Hadari YR: Targeted therapy of the insulin-like growth factor-1 receptor in cancer. Comb Chem High Throughput Screen 11: 62-69, 2008.

30. Schernhammer ES, Holly JM, Pollak MN and Hankinson SE: Circulating levels of insulin-like growth factors, their binding proteins, and breast cancer risk. Cancer Epidemiol Biomarkers Prev 14: 699-704, 2005.

31. Costelli P, Muscaritoli M, Bossola M, Penna F, Reffo P, Bonetto A, Busquets S, Bonelli G, Lopez-Soriano FJ, Doglietto GB, Argilés JM, Baccino FM and Fanelli F: IGF-1 is downregulated in experimental cancer cachexia. Am J Physiol Regul Integr Comp Physiol 291: R674-R683, 2006. 